\title{
A Comparison Study of Radioactivity and Radiation Hazard Index between Legal and Illegal Cigarettes
}

\author{
Muhammad Shafiq Najemee Mohd Ariff, Haslaile Abdullah*, Siti Zura A. Jalil
}

Razak Faculty of Technology and Informatics, Universiti Teknologi Malaysia, Jalan Sultan Yahya Petra, Kuala Lumpur, 54100, MALAYSIA

*Corresponding Author

DOI: https://doi.org/10.30880/ijie.2018.10.07.006

Received 26 October 2018; Accepted 18 November 2018; Available online 30 November 2018

\begin{abstract}
Radioactive nuclide which emits radiation and damages biological tissue is found in the cigarette. Illegal cigarettes are reported to contain higher toxic levels of the nuclide as compared to the legal cigarettes. Therefore, this study aims to compare the radioactive elements, concentration, radiation dose and Radiation Hazard Index (RHI) of the legal and illegal cigarettes. The natural radionuclides of Uranium-238 $\left({ }^{238} \mathrm{U}\right)$, Thorium-232 $\left({ }^{232} \mathrm{Th}\right)$ and Potassium $-40\left({ }^{40} \mathrm{~K}\right)$ of six legal cigarette brands and six illegal cigarette brands were measured using a High Purity Germanium (HPGe) detector-based gamma spectroscopy system. The radioactive elements that were detected by gamma spectrometer were Lead-214 $\left({ }^{214} \mathrm{P}\right)$ and Bismuth-214 $\left({ }^{214} \mathrm{Bi}\right)$ from $238 \mathrm{U}$ decay series, Bismuth-212 $\left({ }^{212} \mathrm{Bi}\right)$ and Actinium-228 $\left({ }^{228} \mathrm{Ac}\right)$ from ${ }^{232} \mathrm{Th}$ decay series and ${ }^{40} \mathrm{~K}$. The activity and concentration of ${ }^{238} \mathrm{U}$ for legal cigarettes were significantly higher than illegal cigarettes $(\mathrm{p}<0.01)$. On the contrary, a significantly high value of activity and concentration of ${ }^{40} \mathrm{~K}$ element of illegal cigarettes were recorded when compared with legal cigarettes $(p<0.001)$. The mean value of RHI for both illegal and legal cigarette samples were calculated and found to be higher than the safe limit of unity (1). However, the statistical test to compare the RHI of internal hazard index $\left(H_{\text {in }}\right)$ and external hazard index $\left(H_{e x}\right)$ between illegal and legal cigarettes was not significant. To conclude, both legal and illegal cigarettes were subjected to a high radiation exposure, which could have negative effects to health.
\end{abstract}

Keywords: Cigarette, smoking, radioactivity, radiation, hazard index, activity, concentration

\section{Introduction}

The smoking initiation age in Malaysia is reported to be between 16.2 years and 18.3 years old (Lim et al., 2010). As these young smokers are mostly still economically dependent on their parents, illegal cigarette, which is cheaper than the legal cigarette in the market, has become the popular choice although this type of cigarette is reported to carry greater health impact due to its high toxic content. Elevated concentrations of toxic metal element particularly lead ( $\mathrm{Pb})$ and cadmium $(\mathrm{Cd})$ in the illegal cigarettes compared to legal cigarettes are reported in several studies. These high levels toxic metals are due to lack of control and regulation in the manufacturing process and growing environment of illegal cigarettes (He, von Lampe, Wood \& Kurti, 2015; Pappas, Polzin, Watson, \& Ashley, 2007). Moreover, the tar, nicotine and carbon monoxide contents of illegal cigarettes are recorded at $60 \%, 80 \%$ and $133 \%$ more than the legal cigarettes, respectively (Swami, Judd, \& Orsini, 2009; Poling, 2012).

For decades, cigarette smoking has become one of the global issues because of its negative impact on health, society, and economy. Cigarette smoking has been identified to be associated with many preventable diseases such as lung cancer, heart-related diseases and other types of cancer, i.e., the cancer of the abdomen, oral cavity, larynx and bladder (Siegel 
et al., 2015). According to WHO report, smoking-related illnesses have caused 7 million deaths per year, and 890,000 of those deaths are caused by second-hand smoke (http://www.who.int/mediacentre/factsheets/fs339/en/, 2018).

Tobacco smoke generates approximately 5000 chemical compounds, which including ammonia, nitrogen oxides, carbon dioxide, carbon monoxide, cobalt, copper, nicotine, and tar (Talhout et al., 2011). Most of these chemicals contained in tobacco smoke are cancer-causing or carcinogens. Exposure to tobacco smoke causes structural damage to some organs, particularly on the heart, lung, liver, and kidneys (Adedayo, Tijani, Musa \& Adeniyi, 2011).

In addition to these chemical substances, radioactive nuclide, taken up from environmental sources, is also identified in the tobacco. Natural radionuclides such as radium, thorium, and potassium, which are present in the soil, fertilizer, water and air, produce natural radiation that also carries health risks. The uranium-radium series such as ${ }^{210} \mathrm{~Pb},{ }^{210} \mathrm{Po}$, and ${ }^{222} \mathrm{Rn}$ are among radionuclides presence in the tobacco (Nain, Chauhan, \& Chakarvarti, 2008). The radiotoxicity of polonium-210 is observed to cause bone marrow failure and damage to vital organs, including the liver and kidney (Harrison, Leggett, Lloyd, Phipps, \& Scott, 2007). Furthermore, intake of ${ }^{210} \mathrm{~Pb}$ and ${ }^{210} \mathrm{Po}$ through the respiratory system causes high incidence of cancer (Skwarzec, Ulatowski, Struminska \& Boryło, 2001). A study in Japan reported that half of the ${ }^{210} \mathrm{Po}$ amount presents in the tobacco are transferred into the smoke, and the other $50 \%$ remain in the ash and the butt (Takizawa, Zhang \& Zhao, 1994).

Currently, little information is available on the radioactivity of cigarettes in Malaysia. In fact, only one study reported on the concentration of polonium-210 in tobaccos and cigarettes in Malaysia (Azman, Rahman \& Yasir, 2013). Hence, the objective of this study is to compare the radioactive elements, concentration, radiation dose and Radiation Hazard Index (RHI) of the legal and illegal cigarettes.

\section{Material and Methods}

\subsection{Cigarette Samples}

Table 1 shows the details on the six cigarette samples we used in this study. The process for sample preparation took place in the Nuclear Physics Laboratory. Firstly, the cigarette filters and papers were removed. The average weight of each cigarettes brand was measured by weighing 60 sticks of each brand on an electronic scale. Then, the samples were dried in a Joven oven at a temperature of $35^{\circ} \mathrm{C}$ for 24 hours to prevent moisture absorption. Each sample was placed in an uncontaminated empty cylindrical plastic container known as Marinelli beaker. Then, the samples in the sealed container were stored for 30 days to bring the ${ }^{238} \mathrm{U},{ }^{232} \mathrm{Th}$, and ${ }^{40} \mathrm{~K}$ and its short life daughter products in equilibrium (Ravisankar et al., 2012). Fig. 1 shows the equipment that was used for this process.

Table 1 - Information on Cigarette Samples.

\begin{tabular}{lccc}
\hline Brand & $\begin{array}{c}\text { Information on cigarette } \\
\text { packs }\end{array}$ & $\begin{array}{c}\text { Price (in } \\
\text { RM) }\end{array}$ & Status \\
\hline S1 & Tar: $12 \mathrm{mg}$, Nicotine: $13 \mathrm{mg}$ & 17.00 & Legal \\
S2 & Tar: $13 \mathrm{mg}$, Nicotine: $11 \mathrm{mg}$ & 12.00 & Legal \\
S3 & No information & 7.50 & Legal \\
S4 & Tar: $14 \mathrm{mg}$, Nicotine: $12 \mathrm{mg}$ & 5.50 & Illegal \\
S5 & No information & 2.00 & Illegal \\
S6 & Tar: $15 \mathrm{mg}$, Nicotine: $13 \mathrm{mg}$ & 4.00 & Illegal \\
\hline
\end{tabular}

a

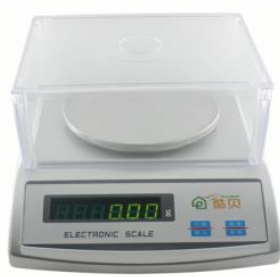

b

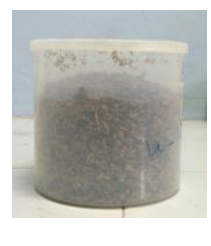

C

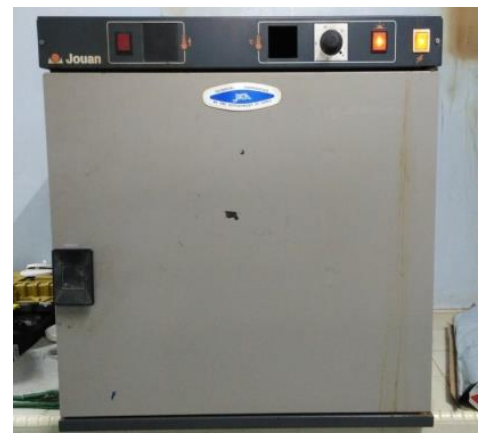

Fig. 1 - Equipment (a) Electronic scale; (b) Marinelli beaker; (c) Joven oven. 


\subsection{High Purity Germanium (HPGe) Detector-based Gamma Spectroscopy System}

HPGe Detector based Gamma Spectroscopy System was used to measure energy spectra of radionuclide in each sample. Due to limited access to the spectroscopy system, the counting time was set at 10800 second. A typical analogue HPGe detector-based gamma spectroscopy system consists of HPGe detector, high voltage power supply, preamplifier, amplifier, Analogue to Digital Converter (ADC), and Multichannel Analyzer (MCA) as shown in Fig. 2.

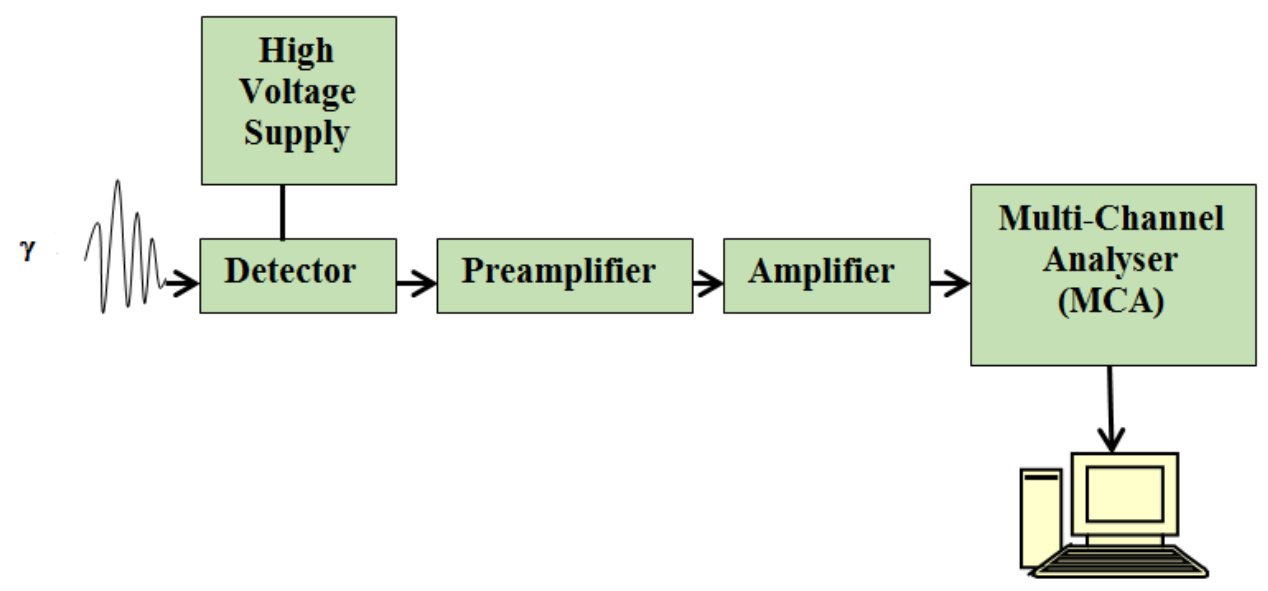

Fig. 2 - Gamma spectrometry system

\subsection{Software}

For the software, this research was conducted on a Windows operating system-based platform and Windows 7 Professional. Genie 2000 and Microsoft Excel were the two main software programs we used to provide the analysis of radionuclides content of the cigarette samples. Genie 2000 Basic Spectroscopy Software was a comprehensive environment for data acquisition, display, and analysis of gamma spectrometry data. The function of Genie 2000 was to qualitatively analyse the energy spectrum and determine the type of radioactive element. Microsoft Excel worksheet was used to calculate the concentration, radiation dose, and Radiation Hazard Index.

\subsection{Concentration of ${ }^{238} \mathrm{U},{ }^{232} \mathrm{Th}$, and ${ }^{40} \mathrm{~K}$}

Radioactivity concentration, $C$ of ${ }^{238} \mathrm{U},{ }^{232} \mathrm{Th}$, and ${ }^{40} \mathrm{~K}$ was calculated by using the equation (1):

$$
C=\frac{A}{M}
$$

$\mathrm{A}=$ Activity of radionuclide in the sample, $\mathrm{Bq}$

$\mathrm{M}=$ Mass of sample $(\mathrm{kg})$

Activity, A can be calculated by using equation (2)

$$
A=\frac{\left(\frac{c}{s}\right)}{\left(\varepsilon \cdot P_{\gamma}\right)}
$$

where

$\stackrel{c}{c}=\underline{\text { number of counts of net peak area sample }- \text { number of counts of net peak area background }}$

$\overline{\mathrm{s}}=\mathrm{counting}$ time

$\varepsilon=$ Efficiency

$\mathrm{P}_{\gamma}=$ Percentage of gamma disintegration, $\%$ 


\subsection{Radiation Dose}

The estimation of radiation dose absorbed per cigarette, $D$, was done by using a conversion coefficient from the absorbed dose in the air to the effective dose and outdoor occupancy factor. $D$ was a total radiation dose calculated for each radionuclide ${ }^{238} \mathrm{U},{ }^{232} \mathrm{Th}$ and ${ }^{40} \mathrm{~K}$. $D$ was determined by the following equation (3):

$$
D=M_{C} \times C \times F \times \text { Absorption factor }
$$

$\mathrm{M}_{\mathrm{c}}=$ Mass of the stick of cigarette

$\mathrm{C}=$ Concentration for each sample, $\mathrm{Bq} / \mathrm{g}$

$\mathrm{F}=$ Coefficient factor for each radionuclide, $\mathrm{nSvBq}^{-1}$

\subsection{Radiation Hazard Index}

The assessment of health hazard index due to radiation exposure of radionuclides content in the cigarette samples was measured by calculating the external $\left(H_{e x}\right)$ and internal $\left(H_{i n}\right)$ hazard index. This index was not only reflecting external radiation exposure of the cigarette, i.e., second-hand smoke, but also the hazard it posed to the internal organs of the body, particularly to the respiratory system. Both values of this index must be less than unity to be regarded as safe and be neglected as radiation hazard (Beretka \& Matthew, 1985). $H_{e x}$ and $H_{i n}$ were calculated by using equation (4) and (5) as defined in (Beretka \& Matthew, 1985).

$$
\begin{aligned}
& H_{e x}=\frac{A_{U}}{370}+\frac{A_{T H}}{259}+\frac{A_{K}}{4810} \leq 1 \\
& H_{i n}=\frac{A_{U}}{185}+\frac{A_{T H}}{259}+\frac{A_{K}}{4810} \leq 1
\end{aligned}
$$

where;

$H_{e x}=$ External Hazard Index

$H_{\text {in }}=$ Internal Hazard Index

$A_{U}=$ Activity Concentration of Uranium

$A_{T H}=$ Activity Concentration of Thorium

$A_{K}=$ Activity Concentration of Potassium

The activity of $A_{U}, A_{T H}$, and $A_{K}$ in each sample was calculated using the equation (2).

\subsection{Statistical Analysis}

Comparison of concentration, radiation dose, and RHI was performed by using Mann-Whitney U-test where the independent variable was the type of cigarette (legal and illegal). IBM SPSS software with significant value set at 0.05 was used to conduct the statistical analysis.

\section{Result and Discussion}

As shown in Table 1, the price of illegal cigarette was approximately 50\% that of the legal cigarettes. Also, tar and nicotine contents of illegal cigarettes were slightly higher as compared to legal cigarettes as reported in other studies (Swami et al., 2009; Poling, 2012). Radionuclides ${ }^{238} \mathrm{U},{ }^{232} \mathrm{Th}$, and ${ }^{40} \mathrm{~K}$, were found in each of the cigarette samples radiated by gamma-ray spectrometer detection system. The elements and energy are summarised in Table 2 . A study of natural radionuclide intake effects to human body has reported a carcinogenic effect of cigarette smoking increased the incidence of lung cancer (Skwarzec et al., 2001). For ${ }^{238} \mathrm{U}$ decay series, two elements were found, namely Lead-214 $\left({ }^{214} \mathrm{~Pb}\right)$ and Bismuth-214 $\left({ }^{214} \mathrm{Bi}\right)$. These elements have standard gamma-ray energy of about $351.87 \mathrm{keV}$ and $609.31 \mathrm{keV}$. They have short half-life around 30 minutes. Meanwhile, for ${ }^{232} \mathrm{Th}$ decay series, there were also two elements found; Bismuth-212 $\left({ }^{212} \mathrm{Bi}\right)$ and Actinium-228 $\left({ }^{228} \mathrm{Ac}\right)$ with gamma ray energy of $727.25 \mathrm{keV}$ and $911.21 \mathrm{keV}$, respectively. These two elements have a longer half-life, which is around 60.6 minutes and 6.13 hours respectively. ${ }^{40} \mathrm{~K}$ was recorded to have $1460.83 \mathrm{keV}$ of gamma-ray energy and the longest half-life, which is $1.3 \times 10^{9}$ years. Based on the energy and half-life of each element, uranium and thorium were easily evaporated due to their short half-life as compared to 
potassium that has high energy value and long half-life. According to (Wannamethee, 1997), smoking and alcohol intake were related to an increase of potassium levels in the blood serum. In another study, the level of potassium in blood serum was reported to relate with health issues that arise from cigarettes smoking behaviour (Muhammad Azfar Azman, 2016). There was also a dose-response relationship with cigarette smoking where the potassium level increased with the increase in cigarettes intake of cigarette smoke per day. Normally, a non-smoker would have a potassium level less than 5.2 $\mathrm{mmol} / \mathrm{litre}$, whereas the smoker is far beyond the values. Also, an increase in the potassium levels from smoking increases the risk of death from non-cardiovascular disease such as lung cancer (Wannamethee, Lever, Shaper \& Whincup, 1997).

Table 2 - Radionuclide Elements.

\begin{tabular}{lccc}
\hline Radionuclide & Elements & Half-life & $\begin{array}{c}\text { Gamma-ray } \\
\text { energy (keV) }\end{array}$ \\
\hline${ }^{238} \mathrm{U}$ & ${ }^{214} \mathrm{~Pb}$ & $26.8 \mathrm{~min}$ & 351.87 \\
& ${ }^{214} \mathrm{Bi}$ & $19.7 \mathrm{~min}$ & 609.31 \\
${ }^{232} \mathrm{Th}$ & ${ }^{212} \mathrm{Bi}$ & $60.6 \mathrm{~min}$ & 727.25 \\
& ${ }^{228} \mathrm{Ac}$ & $6.13 \mathrm{hrs}$ & 911.21 \\
${ }^{40} \mathrm{~K}$ & ${ }^{40} \mathrm{~K}$ & $1.3 \times 10^{9} \mathrm{yrs}$ & 1460.83 \\
\hline
\end{tabular}

The concentrations of ${ }^{238} \mathrm{U},{ }^{232} \mathrm{Th}$ and ${ }^{40} \mathrm{~K}$ in each sample were calculated and are shown in Table 3 . The concentration of ${ }^{238} \mathrm{U}$ of sample S3 was identified as the highest at $0.66 \mathrm{~Bq} / \mathrm{g}$ as compared to others. On the contrary, the sample S6 showed the lowest concentration at $0.15 \mathrm{~Bq} / \mathrm{g}$. The amount of ${ }^{238} \mathrm{U}$ concentration for illegal cigarettes ranged between 0.15 and $0.20 \mathrm{~Bq} / \mathrm{g}$. The concentration of ${ }^{232} \mathrm{Th}$ decay series for the legal cigarettes of sample S2 showed the highest concentration at $1.93 \mathrm{~Bq} / \mathrm{g}$ as compared to sample S3, which showed the lowest concentration, $0.98 \mathrm{~Bq} / \mathrm{g}$. The legal cigarettes produced the highest and the lowest ${ }^{232} \mathrm{Th}$ concentration as compared to illegal cigarettes, which showed concentrations below $1.67 \mathrm{~Bq} / \mathrm{g}$. The ${ }^{40} \mathrm{~K}$ element in illegal cigarettes of sample S5 marked the highest concentration value, which was $20.10 \mathrm{~Bq} / \mathrm{g}$. The lowest concentration was shown by sample $\mathrm{S} 2$ at $10.51 \mathrm{~Bq} / \mathrm{g}$. The concentration of ${ }^{238} \mathrm{U}$ in the legal cigarettes was significantly higher than in the illegal cigarettes $(\mathrm{p}<0.01)$. On the contrary, a significantly high value of concentration of ${ }^{40} \mathrm{~K}$ element in illegal cigarettes was recorded when compared with legal cigarettes $(\mathrm{p}<0.001)$.

Comparing our results with other reported study available in the literature, the concentration of ${ }^{238} \mathrm{U},{ }^{232} \mathrm{Th}$ and ${ }^{40} \mathrm{~K}$ in the cigarette samples ranged from $0.061 \mathrm{~Bq} / \mathrm{g}$ to $0.153 \mathrm{~Bq} / \mathrm{g}, 0.028 \mathrm{~Bq} / \mathrm{g}$ to $0.042 \mathrm{~Bq} / \mathrm{g}$ and $0.75 \mathrm{~Bq} / \mathrm{g}$ to $2.232 \mathrm{~Bq} / \mathrm{g}$, respectively (Nain et al., 2010). In another study on the radionuclides' concentration in the soil of tobacco farm, the values were recorded in the range of $2.55-3.21 \mathrm{~Bq} / \mathrm{g}$ for ${ }^{40} \mathrm{~K}$ and $0.034-0.065 \mathrm{~Bq} / \mathrm{g}$ for ${ }^{232} \mathrm{Th}$ (Jibiri \& Biere, 2011). The average value of concentration for the cigarette samples measured in this study was slightly higher than the value reported in the aforementioned study. These variations could be due to various factors, namely, the radioactive content in the farm soil on which the tobacco used in the cigarettes was grown, the location of the farm, and also the cigarette manufacturing process. Tobacco plants have been observed to accumulate a higher concentration of radioactive elements taken up by the roots in their leaves (Shousha \& Ahmad, 2011). The processing, packaging and other technological processes, including the use of additives for bringing raw food materials to consumers, can significantly increase radioactive contents in cigarettes (Shousha \& Ahmad, 2011). Furthermore, the radioactive contents of the cigarettes also varied depending on the geographical area of tobacco production (Durusoy \& Yildirim, 2017). It was found at this point of this study that, nevertheless, it has not been possible for the researcher to get any evidence from this study to explain whether differences are related to the area of production or the extent of industrial development of the area.

Table 3 - Concentration $(\mathrm{C})$ of ${ }^{238} \mathrm{U},{ }^{232} \mathrm{Th}$ and ${ }^{40} \mathrm{~K}$ for each cigarette sample weighing 42 grams.

\begin{tabular}{cccc}
\hline Sample & \multicolumn{3}{c}{$\mathbf{C}(\mathbf{B q} / \mathbf{g})$} \\
\cline { 2 - 4 } & ${ }^{\mathbf{2 3 8}} \mathbf{U}$ & ${ }^{\mathbf{2 3 2}} \mathbf{T h}$ & ${ }^{\mathbf{4 0}} \mathbf{K}$ \\
\hline S1 & 0.38 & 1.57 & 15.99 \\
S2 & 0.20 & 1.93 & 10.51 \\
S3 & 0.66 & 0.98 & 14.62 \\
S4 & 0.18 & 1.11 & 16.90 \\
S5 & 0.20 & 1.56 & 20.10 \\
S6 & 0.15 & 1.67 & 16.90 \\
\hline
\end{tabular}


From Table 4, the radiation dose of ${ }^{40} \mathrm{~K}$ decay series per stick of both types of cigarettes was the highest as compared to ${ }^{238} \mathrm{U}$ and ${ }^{232} \mathrm{Th}$. However, only ${ }^{40} \mathrm{~K}$ and ${ }^{238} \mathrm{U}$ decay series were statistically significant between illegal and legal cigarettes $(\mathrm{p}<0.01)$. The illegal cigarette sample S5 was observed to give the highest total radiation dose of $87.49 \mathrm{nSv}$ per stick, whereas the lowest dose of $45.88 \mathrm{nSv}$ was recorded in the legal cigarette sample of S2. The total radiation dose for illegal cigarettes was significantly higher than legal cigarettes $(\mathrm{p}<0.005)$ but that value was much lower than the average worldwide exposure to natural radiation sources value of $2.4 \mathrm{mSv}$ (UNSCEAR, 2000).

Table 4 - Radiation dose (D) per stick of cigarette weight of 0.7 gram.

\begin{tabular}{ccccc}
\hline Sample & \multicolumn{3}{c}{$\mathbf{D}(\mathbf{n S v})$} & $\begin{array}{c}\text { Total Radiation Dose, } \\
\mathbf{D}(\mathbf{n S v})\end{array}$ \\
\cline { 2 - 3 } & ${ }^{\mathbf{2 3 8}} \mathbf{U}$ & ${ }^{\mathbf{2 3 2}} \mathbf{T h}$ & ${ }^{\mathbf{4 0}} \mathbf{K}$ & 69.76 \\
S1 & 0.24 & 0.13 & 69.39 & 45.88 \\
S2 & 0.12 & 0.16 & 45.60 & 63.94 \\
S3 & 0.42 & 0.08 & 63.44 & 73.56 \\
S4 & 0.11 & 0.09 & 73.36 & 87.49 \\
S5 & 0.13 & 0.13 & 87.23 & 73.59 \\
S6 & 0.09 & 0.14 & 73.36 & \\
\hline
\end{tabular}

Fig. 3 clearly shows that for all the cigarette samples RHI value exceeds the limit of the hazard index, which is 1 . For external hazard index $H_{e x}$, the highest value was recorded by sample S2 at 10.749. The lowest value for external hazard was for S4 at 8.254, which, however, exceeds the safe limit. For $H_{\text {in }}$, the result showed that sample S1 was the highest among the samples at 11.449. The lowest value was obtained from sample S4, which was 9.014. The internal hazard index, $H_{\text {in }}$ in all samples was higher than the external hazard index, $H_{e x}$. This high value of internal hazard index, $H_{\text {in }}$ was an indication of the higher risk it posed to internal organs, particularly to the respiratory organs. The statistical test to compare $H_{i n}$ and $H_{e x}$ between illegal and legal cigarettes was not significant. Therefore, the exposure to radiation due to both types of cigarettes poses equal health risk to the internal organs of smokers, and of the harmful effects of second-hand smoke.

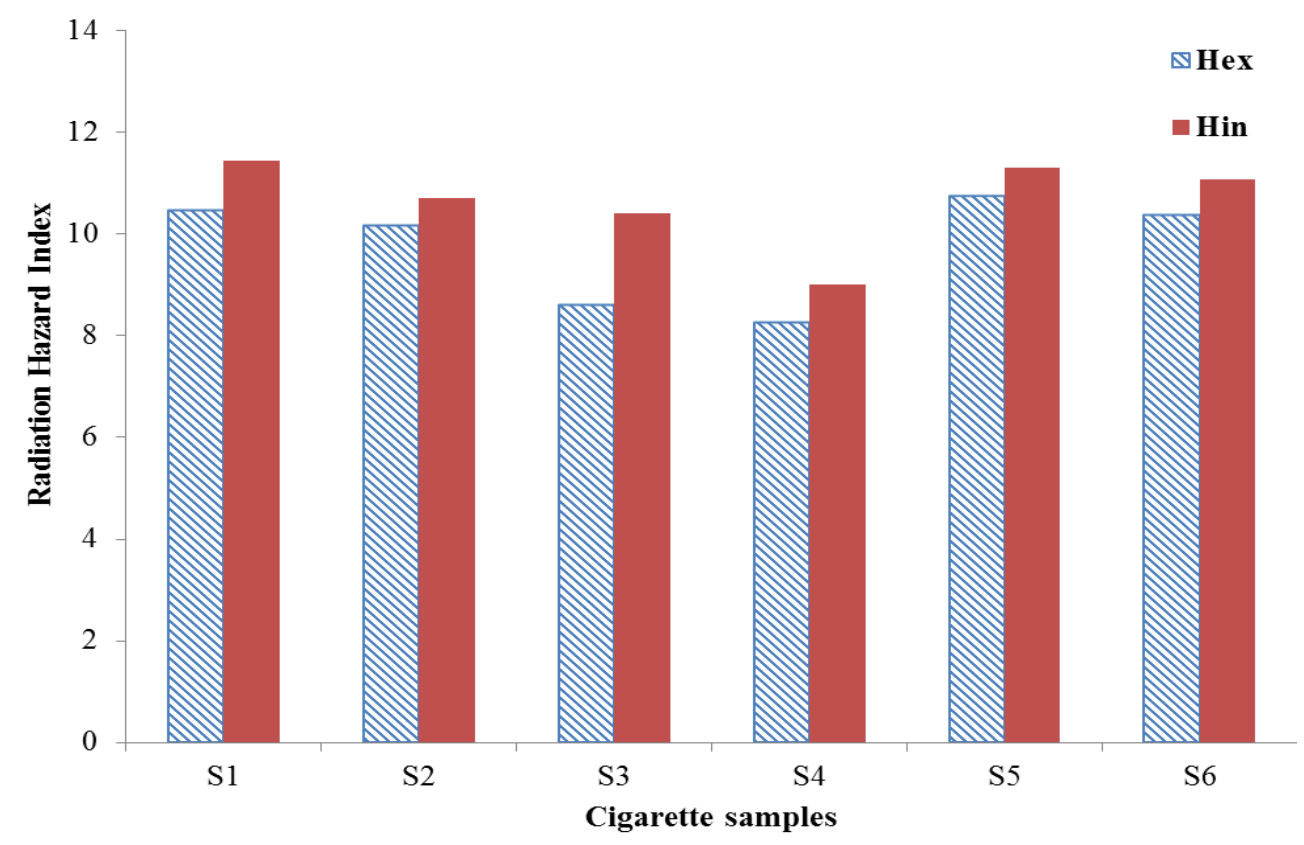

Fig. 3 - Radiation Hazard Index $\left(\mathrm{H}_{\mathrm{ex}}\right.$ and $\left.\mathrm{H}_{\mathrm{in}}\right)$ for legal cigarette (S1, S2, S3) and illegal cigarette (S4, S5, S6)

Among the limitations of our study was the limited access to the HPGe system which afforded us a short counting time for measuring the cigarette samples on the detector. In our study, the sample time of the detector was $10800 \mathrm{~s}$ compared to other studies, e.g., 36000 s (Jibiri \& Biere, 2011), 72000s (Nain et al., 2010) and 114000 s (Azman et al., 2013). Secondly, a smaller amount of cigarette mass, i.e., $60 \mathrm{~g}$ for each cigarette brand was used in this study, whereas an average of 100-400 g samples were used in (Jibiri \& Biere, 2011; Nain et al., 2010). These two factors of counting time and sample mass determined the value of radioactivity concentration and radiation dose derived from the equations (1), (2) and (3). 


\section{Conclusion}

In this study, six cigarette brands, three each of legal and illegal brands, were analysed to identify their concentration of radioactive elements, radiation dose, and hazard index. A statistical comparison between the measured values obtained from the legal and illegal cigarette samples was performed. The radioactive elements that were detected in all the cigarette samples by gamma spectrometer were ${ }^{214} \mathrm{~Pb}$ and ${ }^{214} \mathrm{Bi}$ from ${ }^{238} \mathrm{U}$ decay series, ${ }^{212} \mathrm{Bi}$, and ${ }^{228} \mathrm{Ac}$ from ${ }^{232} \mathrm{Th}$ decay series and ${ }^{40} \mathrm{~K}$. The concentration of uranium, thorium, and potassium in the samples for legal cigarettes were higher than illegal cigarette samples. Results from the estimation of radiation dose absorbed per cigarette showed that the illegal cigarettes were more harmful as compared to the legal cigarettes, based on their higher values. In the assessment of radiation hazard index of legal and illegal cigarettes, it was concluded that both internal and external hazard indexes for all samples were above the accepted radiation safe limit. Therefore, both legal and illegal cigarettes caused high radiation exposure that could further cause a hazard to health. Future work must include more cigarette samples for comparison of the legal and illegal cigarettes natural radioactivity content.

\section{Acknowledgement}

This research was funded by Research University Grant (Vot No. 15H54) from Universiti Teknologi Malaysia. The authors thank the Research Management Centre UTM and the Malaysian Ministry of Education for their financial support and cooperation.

\section{References}

[1] Lim, K. H., Sumarni, M. G., Kee, C. C., Norhamimah, A., Wan Rozita, W. M., \& Amal, N. M. (2010). Prevalence, smoking habit and factors related to smoking and nicotine addiction among lower secondary school male students in Kota Tinggi district, Johor, Malaysia. Malaysian Journal of Public Health Medicine, 10(1), 28-37.

[2] He, Y., von Lampe, K., Wood, L., \& Kurti, M. (2015). Investigation of lead and cadmium in counterfeit cigarettes seized in the United States. Food and Chemical Toxicology, 81, 40-45.

[3] Pappas, R. S., Polzin, G. M., Watson, C. H., \& Ashley, D. L. (2007). Cadmium, lead, and thallium in smoke particulate from counterfeit cigarettes compared to authentic US brands. Food and Chemical Toxicology, 45(2), 202-209.

[4] Swami, K., Judd, C. D., \& Orsini, J. (2009). Trace metals analysis of legal and counterfeit cigarette tobacco samples using inductively coupled plasma mass spectrometry and cold vapor atomic absorption spectrometry. Spectroscopy Letters, 42(8), 479-490.

[5] Poling, J. (2012), Smoke Signals: The Native Takeback of North America's Tobacco Industry, Canada: Dundurn Press.

[6] Siegel, R. L., Jacobs, E. J., Newton, C. C., Feskanich, D., Freedman, N. D., Prentice, R. L., \& Jemal, A. (2015). Deaths due to cigarette smoking for 12 smoking-related cancers in the United States. JAMA internal medicine, 175(9), 1574-1576.

[7] http://www.who.int/mediacentre/factsheets/fs339/en/ (Updated March 2018)

[8] Talhout, R., Schulz, T., Florek, E., Van Benthem, J., Wester, P., \& Opperhuizen, A. (2011). Hazardous compounds in tobacco smoke. International journal of environmental research and public health, 8(2), 613-628.

[9] Adedayo, A. D., Tijani, A. A., Musa, A. A., \& Adeniyi, T. D. (2011). Histological study of smoke extract of Tobacco nicotiana on the heart, liver, lungs, kidney, and testes of male Sprague-Dawley rats. Nigerian medical journal: journal of the Nigeria Medical Association, 52(4), 217.

[10] Nain, M., Chauhan, R. P., \& Chakarvarti, S. K. (2008). Alpha radioactivity in tobacco leaves: Effect of fertilizers. Radiation Measurements, 43, 515-519.

[11] Harrison, J., Leggett, R., Lloyd, D., Phipps, A., \& Scott, B. (2007). Polonium-210 as a poison. Journal of Radiological Protection, 27(1), 17.

[12] Skwarzec, B., Ulatowski, J., Struminska, D. I., \& Boryło, A. (2001). Inhalation of 210Po and 210Pb from cigarette smoking in Poland. Journal of Environmental Radioactivity, 57(3), 221-230.

[13] Takizawa, Y., Zhang, L., \& Zhao, L. (1994). 210Pb and 210Po in tobacco-with a special focus on estimating the doses of 210Po to man. Journal of radioanalytical and nuclear chemistry, 182(1), 119-125.

[14] Azman, M. A., Rahman, I. A., \& Yasir, M. S. (2013, May). 210 Po concentration analysis on tobacco and cigarettes in Malaysia. In AIP Conference Proceedings (Vol. 1528, No. 1, pp. 417-422). AIP.

[15] Ravisankar, R., Vanasundari, K., Chandrasekaran, A., Rajalakshmi, A., Suganya, M., Vijayagopal, P., \& Meenakshisundaram, V. (2012). Measurement of natural radioactivity in building materials of Namakkal, Tamil Nadu, India using gamma-ray spectrometry. Applied Radiation and Isotopes, 70(4), 699-704.

[16] Beretka, J., \& Matthew, P. J. (1985). Natural radioactivity of Australian building materials, industrial wastes and by-products. Health physics, 48(1), 87-95.

[17] Wannamethee, S. G., Lever, A. F., Shaper, A. G., \& Whincup, P. H. (1997). Serum potassium, cigarette smoking, and mortality in middle-aged men. American journal of epidemiology, 145(7), 598-606. 
[18] Nain, M., Gupta, M., Chauhan, R. P., Kant, K., Sonkawade, R. G., \& Chakarvarti, S. K. (2010). Estimation of radioactivity in tobacco.

[19] Jibiri, N. N., \& Biere, P. E. (2011). Activity concentrations of 232Th, 226Ra and 40K and gamma radiation absorbed dose rate levels in farm soil for the production of different brands of cigarette tobacco smoked in Nigeria.

[20] Shousha, H. A., \& Ahmad, F. (2011). Natural radioactivity contents in tobacco and radiation dose induced from smoking. Radiation protection dosimetry, 150(1), 91-95.

[21] Durusoy, A., \& Yildirim, M. (2017). Determination of radioactivity concentrations in soil samples and dose assessment for Rize Province, Turkey. Journal of Radiation Research and Applied Sciences, 10(4), 348-352.

[22] United Nation Scientific committee on the effects of Atomic Effects of Atomic Radiation (UNSCEAR) (2000). Radiation sources and effects of ionizing radiation. New York, USA: United Nations. Report of the United Nation Scientific Committee on the effect of Atomic Radiation to General Assembly. 